\title{
Medicalização da infância: produções de sentido sobre o discurso de profissionais de saúde
}

Jerto Cardoso da Silva. Universidade de Santa Cruz do Sul

Caroline Forati Mendes. Universidade Lusófona de Humanidades e Tecnologias

\section{Resumo}

O presente estudo visa compreender quais os sentidos atribuídos à medicalização dos cuidados preconizados à saúde mental na infância por profissionais de saúde que atendem crianças e adolescentes em serviços de saúde. Desse modo, buscou-se dar visibilidade às produções de sentido através da Análise de Discurso. Almejamos compreender quais os significados que emergem nos depoimentos desses profissionais, quando questionados, através de entrevistas semiestruturadas, sobre as formas cuidados destinados à infância frente ao tratamento medicamentoso. Os sentidos mais frequentes referem à medicalização como instância primeira e imediata de cuidados destinados à infância. A lógica medicalizante prepondera devido ao desempoderamento e fragilidades das figuras parentais por um lado e, por outro, o acesso à informação tem sido fundamental para repensar a relação entre consumo, indústria farmacêutica e saúde mental.

Palavras-chave: medicalização; infância; discurso.

\begin{abstract}
Childhood medicalization: productions of meaning on the discourse of health professionals. This study aimed to understand which senses are attributed to the medicalization of care recommended to mental health in childhood by professionals who serve children and adolescents in health services. For this investigation, the methodology it was used the Discourse Analysis, thus giving visibility to the productions of meaning of each patient. The aim of this study was to understand the reasons that emerge in the speech of these professionals, when questioned, through semi-structured interviews, about the ways of care destined for childhood in relation to medicine's treatment. The findings show that the medications are pointed out as the first form of care intended for childhood. The logic that was found in this research points to the use of medicines as a means to supply the absence of one of the family figures, as well as access to information that would call into check for consumption, the pharmaceutical industry and mental health.
\end{abstract}

Keywords: medicalization; childhood; discourse.

\section{Resumen}

Medicalización de la infancia: producciones de sentido sobre el discurso de profesionales de salud. El presente estudio tiene como objetivo comprender los significados atribuidos a la medicalización de la atención recomendada para la salud mental infantil por profesionales de la salud que ayudan a niños y adolescentes en los servicios de salud. Por lo tanto, buscamos dar visibilidad a la producción de significado a través del análisis del discurso. Nuestro objetivo es comprender los significados que surgen en los testimonios de estos profesionales, cuando se les pregunta, a través de entrevistas semiestructuradas, sobre las formas de atención destinadas a los niños frente al tratamiento farmacológico. Los significados más frecuentes se refieren a la medicalización como la primera instancia inmediata de cuidado de niños. La lógica medicalizante prevalece debido a la falta de poder y las debilidades de las figuras parentales, por un lado, y, por otro, el acceso a la información ha sido fundamental para repensar la relación entre el consumo, la industria farmacéutica y la salud mental.

Palabras clave: medicalización; la infancia; discurso. 
O acesso a serviços públicos de saúde tem disponibilizado, em especial os serviços de saúde mental, uma expansão do tratamento medicamentoso. Muitas vezes, antes de qualquer outra possibilidade o medicamento passa a ser a forma de cuidado imediato, constituindo-se como tratamento prioritário (La Gestion Autonome de la Médication en Santé Mentale [GAM], 2006). Junto a isso, a falta de informação dos pacientes/usuários sobre o que é prescrito, os efeitos colaterais, a supermedicação, e a não discussão de outras possibilidades de cuidado têm produzido alguns efeitos indesejados no tratamento, tais como o abandono ou desistência, o uso indiscriminado de medicamentos e, em muitos casos, nota-se um agravamento do quadro (GAM, 2016). Esses achados nos fazem pensar na importância de reconhecer as experiências e o saber dos usuários e o impacto dos medicamentos sobre suas vidas, em especial das crianças e suas famílias.

Entre 1960 e 70, as reflexões sobre a medicalização surgem nas produções acadêmicas. Tal preocupação foi motivada pelo incremento e disseminação dos serviços biomédicos na sociedade através do acesso e da comercialização crescente de fármacos. O filósofo Illich é bastante contundente nas suas críticas à iatrogenização da sociedade e conceitualiza o termo medicalização da vida humana. A partir de então o termo se populariza e se amplia. Críticas são produzidas, pois, se por um lado, os medicamentos atuam nos desvios de normas sociais, por outro, eles também ajudam muitos a viverem de forma mais qualitativa. A crítica então se amplia dos medicamentos para o poder biomédico e destaca o posicionamento mais ativo dos sujeitos na sociedade atual. Ou seja, o termo medicalização do social é relativizado frente à complexidade das sociedades contemporâneas e das formas mais ativa de participação dos pacientes via movimentos sociais e políticas públicas. Apesar disso, as relações profissionais-pacientes ainda são bastante assimétricas e atravessadas pela indústria farmacológica. A tentativa é escapar das polaridades nessa questão, na qual o profissional ou o paciente passam a ser culpabilizados (Metzl \& Herzig, 2007). Essa pesquisa tenta encaminhar as reflexões para um aprofundamento mais profícuo dessa relação na qual a dimensão do político a constitui. Portanto,

entende-se por medicalização o processo por meio do qual as questões da vida social - complexas, multifatoriais e marcadas pela cultura e pelo tempo histórico - são reduzidas a um tipo de racionalidade que vincula artificialmente a dificuldade de adaptação às normas sociais a determinismos orgânicos que se expressariam no adoecimento do indivíduo (Conselho Federal de Psicologia [CFP], 2015, p. 11).

Faz-se, então, necessário refletir sobre as formas de cuidar, sobre os sentidos que fundam e constituem esses procedimentos, efeitos das formas como se pensa a medicalização das crianças e, consequentemente, refletir sobre o que se propõe como cuidado nos serviços de saúde pública destinados à infância.

Este estudo busca compreender e problematizar as falas dos profissionais de saúde referentes à medicação psicofarmacológica e às formas de cuidado às crianças e adolescentes em sofrimento psíquico. Busca também desnaturalizar esses discursos e as condições de sua constituição, procurando dar visibilidade às produções de sentidos construídos sob determinadas condições políticas e históricas que impulsionam práticas de cuidados à saúde e seus desdobramentos.

Dentro desse objetivo, este estudo busca analisar, sob a perspectiva da tendência francesa de Análise do Discurso, doravante denominada AD, os discursos formulados sobre os cuidados dispensados à infância $e$ à adolescência e, portanto, à saúde, a partir dos depoimentos de profissionais de saúde.

Para tanto, precisamos entender quando o tratamento medicamento começou a ser considerado e, posteriormente, preponderante nas formas de cuidado nessa faixa etária. A psicofarmacologia surge no final da década de $40 \mathrm{com}$ a introdução dos primeiros psicofármacos que foram inicialmente desenvolvidos para o tratamento de transtornos mais graves. A partir de então, a psiquiatria amplia o seu estatuto de ciência, deixando de ser uma disciplina voltada exclusivamente para o tratamento da loucura e passando a medicar também os pequenos "malestares" cotidianos e a "dor-de-existir". Ao longo dessas décadas, observamos um consequente aumento da medicalização para as dificuldades psíquicas e emocionais (J. T. Rodrigues, 2003).

Gaudenzi e Ourtega (2012) fazem uma retomada sobre o termo medicalização, conceituando-o a partir de Illich, abordando na sua hipertrofia na modernidade, e Foucault na perspectiva do biopoder, ou seja, um poder sobre a vida exercida sobre os corpos dos sujeitos, regulando-os. O termo medicalização surge no final da década de 1960, referindo-se à apropriação dos meios de vida do homem pela medicina e da sua intervenção política no meio social que extrapola o seu campo tradicional de ação direta sobre as moléstias. Portanto, um dos riscos da medicalização é transformar 
modos de existência em processos patológicos, além de impulsionar a prescrição abusiva de medicamentos ou ainda contribuir com o uso desnecessário de procedimentos e serviços, entre outros. Sendo assim, o termo medicalização não está apenas ligado à utilização de medicamentos, pois está presente na iatrogenia da vida.

Quando os primeiros psicofármacos se tornaram disponíveis, houve uma resistência bastante grande da comunidade psicanalítica em relação ao seu uso durante o tratamento, pois a medicação era vista como uma intrusão indesejada no tratamento, já que causava a supressão dos sintomas, interferia no estabelecimento da transferência e favorecia a resistência. Já por outro lado, era defendida pelos farmacologistas a ideia de que a psicoterapia além de desnecessária era também danosa, já que mantinha os pacientes em permanente preocupação quanto aos seus conflitos. (Frey, Mabilde, \& Eizirik, 2004).

Apesar dessa polêmica, destaca Montero (1994), as medicações foram se tornando centrais no tratamento dos problemas psíquicos, através da aquisição do "status" de "cura por si mesmo", e os serviços psicológicos, consequentemente, assumindo um caráter de desnecessários frente à presença da medicação, visto que, conforme J. T. Rodrigues (2003), acreditava-se que a medicação era capaz de devolver ao paciente a alegria, tranquilidade e capacidade produtiva.

Tais aspectos, aliados à ideia vigente de "cura mágica" pela medicação, podem ter impulsionado os médicos à prescrição dos psicofármacos para um maior número de casos, trazendo como consequências a generalização do uso da medicação, além da popularização dos diagnósticos psiquiátricos, que com facilidade convertem características humanas em patologias (Kimura, 2005).

Calazans e Lustoza (2008, p. 3), acreditam que "a medicalização é uma proposta equivocada, pois pretende uma objetivação de algo que não é científico: o sujeito". Nesse sentido, Lefèvre (1987), expõe que o medicamento pode ser usado como uma forma de poupar a dor e o sofrimento das pessoas, fazendo desaparecer os sintomas, as dificuldades sociais e as pessoais. Ou seja, sendo um simulacro de cura, pois embora os sintomas da dor e do sofrimento possam ser camuflados, eles continuam a agir de uma outra forma.

Porém, Sigal (2009) chama a atenção para o fato de que atualmente a medicação prevalece à análise da história, à descoberta do que não foi metabolizado na relação com o outro, à elaboração e construção, configurando-se em um atalho para amenizar as angústias. Com esse movimento, portanto, estas angústias
- produzidas na interação com o meio - podem ser caladas e a subjetividade dos indivíduos triturada, limitando a sua capacidade de agir sobre si, conforme expuseram Barrio, Perron e Ouellette (2008).

Apesar disto, expõe M. A. P. Rodrigues, Facchini e Lima (2006), o que se observa atualmente é que, entre o medo da desordem e a valorização de uma competitividade baseada unicamente no sucesso material, muitas pessoas preferem fazer o uso de substâncias químicas a falar de seus sofrimentos íntimos, vinculando-se à promessa dos atuais medicamentos de extermínio total dos sintomas em pouco tempo. O silêncio passa então a ser preferível à linguagem, fonte de angústia e vergonha, conforme Roudinesco (2000), tal silenciamento do sintoma, muitas vezes, não dissipa o sofrimento.

Nessa perspectiva, Sigal (2009) enfatiza que nossa própria realidade pode ser vista como produtora de patologias, através do consumo desenfreado, da exigência por satisfação pulsional imediata, da falta de solidariedade, entre outros aspectos. E tudo isso, continua a autora, contribui para transformar o sujeito em objeto, atacando seus processos criativos e intelectuais, colocando-se em posição de falência. Essa evitação do mal-estar incentiva a busca de uma técnica que seja capaz de reduzir ou eliminar o sintoma psíquico, sendo este equivocadamente tratado da mesma forma que um sintoma objetivável (Calazans \& Lustoza, 2008).

O consumo de psicofármacos é, portanto, uma tecnologia de si que se encontra intensificada e naturalizada nos corpos, a qual passou a definir as condições de saúde de uma sociedade ao silenciá-los. Esta tecnologia se consolidou como o sentido atribuído à saúde neste meio e, enquanto estes modos de vida sobreviverem, sempre haverá fluoxetinas, sertralinas, diazepams, alprazolams (Nardi, 2007, p. 15).

O aumento da prescrição e consequente o consumo de psicofármacos por crianças tem inquietado a sociedade. Conforme Bezerra (2008), entre 2000 e 2002, as prescrições de antidepressivos para esta faixa etária aumentaram $48 \%$ no Brasil e $68 \%$ entre as crianças britânicas. Uma grande preocupação existente quanto ao uso de psicofármacos na infância, refere-se ao impacto que o tratamento terá no cérebro infantil, já que não há ainda respostas conclusivas pela ciência sobre o efeito desses medicamentos no sistema nervoso central. Segundo Raeburn (2009), além do suicídio, há evidências de que alguns remédios também interferem no processo de desenvolvimento e maturação 
do cérebro infantil. Então muitas crianças que tomam esses medicamentos conseguem alívio em curto prazo, mas mais tarde acabam desenvolvendo outros problemas psíquicos.

Sem a possibilidade de expressar simbolicamente e construir elaborações psíquicas sobre o seu sofrimento e dor, as crianças muito cedo são privadas de um enfrentamento psíquico a problemas de ordem multifaltorial. A medicação indiscriminada dos desajustes na infância pode acarretar problemas físicos, devido aos diversos efeitos colaterais e promover fragilidades na relação da criança com seu corpo e com o outro.

De acordo com Pundik (2009), milhões de crianças de gerações anteriores, que davam trabalho aos adultos em função da sua curiosidade e intensidade de suas atividades, salvaram-se do diagnóstico de hiperatividade, talvez pelo fato de o Manual Diagnóstico e Estatístico dos Transtornos Mentais (DSM) não ter existido até 1952. Conforme o autor, desde a elaboração do Manual está cada vez mais difícil de estabelecer o limite entre "o normal" e "o anormal", tendo em vista que há tratamentos medicamentosos para cada uma de suas descrições classificatórias.

No intuito de ampliar essa discussão, o presente estudo busca compreender os sentidos que se produzem nas falas dos profissionais de saúde frente à complexidade do ato de cuidar e o uso da medicação. A infância, na atualidade, é transversalizada pelo fenômeno da medicalização, conceito polissêmico, mas que, de forma geral, refere-se ao processo artificial que transforma questões políticas e sociais em individuais, que pode, nesse raciocínio, desencadear diversas práticas de cuidado, entre elas a medicamentalização, isto é, nessa perspectiva, lidar com problemas ligados à saúde mental os transformando em intervenções biologizantes e individualizantes e que podem ou não desencadear uso abusivo/excessivo de medicamentos e/ou serviços de saúde. O termo "medicamentalização" se refere à lógica de intervir em problemas e situações que envolvem a complexidade da vida humana e seus sofrimentos na espera mental e psicossocial dentro de numa racionalidade organicista e de prescrição farmacológica como forma primordial de cuidado. Portanto, a medicamentalização pode ser considerada uma das consequências da medicalização (Ministério da Saúde, 2018).

\section{Metodologia}

Realizamos a pesquisa através de entrevistas semiestruturadas com profissionais de saúde mental que atendem crianças medicadas, visando uma análise qualitativa. Solicitamos que comentassem sobre: a vinculação com o serviço, as formas de cuidado no serviço, as suas percepções sobre o cuidado e os cuidadores, as suas concepções sobre medicalização da sociedade e da infância na sua prática. Questões como: Quais são suas atividades mais frequentes?; Quem é o usuário do serviço?; Quais as formas de cuidado nesse serviço?; O que você pensa sobre o cuidar na atualidade?; O que é cuidar?; Quem são os responsáveis pelo cuidado atualmente?; Em que momento a tua intervenção é acionada como a forma de cuidado?; Em relação a medicação como você a percebe atualmente; Você considera que as crianças e adolescentes estão medicalizados?; entre outras, compuseram a entrevista.

Em pesquisas qualitativas, Orlandi (1999) afirma que todo dispositivo de interpretação precisa de um artefato teórico para que se efetue. A Análise de Discurso visa à compreensão de como um objeto simbólico produz sentidos, como ele está investido de significância para e pelos sujeitos. É dentro desse dispositivo teórico que pretendemos construir um aparato analítico de interpretação que possibilite compreender regularidades, opacidades e transformações.

Partimos, assim, da superfície linguística, os depoimentos, para chegar ao espaço discursivo, pois, pela análise dessas duas dimensões (linguística e discursiva), podemos apontar algumas regularidades e instabilidades do processo discursivo. É nesse espaço que pretendemos trabalhar o discurso, isto é, a relação entre língua, sujeito, historicidade, ideologia e inconsciente para, enfim, chegarmos às produções de sentido sobre o cuidar. Com esses pressupostos, realizamos as análises dos depoimentos dos sujeitos, que formaram o arquivo principal de nosso estudo. A partir dele, selecionamos várias sequências discursivas que compuseram o nosso corpus e selecionamos algumas que se transformaram em unidades discursivas de análise. As entrevistas foram identificadas com códigos: inicial do serviço, profissão e número.

O estudo teve suas análises nos depoimentos de nove profissionais de saúde Tínhamos como critério de inclusão, serem técnicos responsáveis pelos cuidados de crianças medicadas com psicofármacos e atendidas em diferentes serviços de saúde mental. Entramos em contato com as coordenações dos serviços que indicaram, via reunião de equipe, os profissionais que se dispuseram a participar e fomos até o local realizar a entrevista. A partir daí, investigamos a(s) representação(ões) destes sobre o cuidar e o uso de medicação. Portanto, 
até nesse momento, foram entrevistados os profissionais de diferentes serviços públicos de saúde mental no sul do país, que se dispuserem a participar da pesquisa.

Conforme a resolução 466/12, este trabalho foi submetido ao Comitê de Ética de uma Universidade Comunitária, por se tratar de um estudo com seres humanos. Desse modo, antes iniciarmos a pesquisa, os participantes foram informados sobre os objetivos propostos pelo estudo, consentiram e assinaram um Termo de Consentimento Livre e Esclarecido (TCLE).

\section{Resultados e discussão}

Realizamos entrevistas com profissionais de saúde (psicólogos, médicos, enfermeiros) que trabaIham em serviços que atendem crianças e adolescentes: Serviços-escola (4), Centro de Atenção Psicossocial da Infância e Adolescência CAPSia (2), Centro de Atendimento Municipal Especializado (2) e Hospital (1) no interior do RS.

Como diz Foucault (1977), a história dos sujeitos não fica indiferente à medicalização, desde o século XVIII a rede medicalização tem se intensificado, ficando cada vez mais densa e ampla. Isso devido ao desenvolvimento da área médica e abrangências das instituições e serviços de saúde movida por um consumo e indústria farmacêutica. Essa articulação entre saúde e economia capitalista, a torna individual ou individualizante, mas para isso, se engendra como medicina social fundada numa tecnologia do corpo social. As tecnologias de saúde são práticas sociais que imprimem, nas relações humanas, formas de subjetivação via controle dos corpos. Para Foucault a medicina é uma estratégia biopolítica, portanto os cuidados à saúde humana não são imparciais e inócuos, atuando para além da produção do bem, pois neles se constroem e (re) produzem formas e modos de viver e de se relacionar com o outro. Podemos notar isso nas respostas de alguns de nossos entrevistados:

[...] Tem uma oferta da indústria farmacêutica muito grande, têm muitos produtos à disposição, tem um marketing forte disso, e tem também a questão da exigência da gente estar sempre potente né [... ] eu tenho que usar coisas que me deixem cada vez mais potentes, e essas coisas existem, existe essa oferta (SE1).

"[...] além de, obviamente, o interesse das indústrias farmacêuticas" (SM1). A indústria farmacêutica é a segunda em faturamento no mundo, perdendo apenas para a indústria bélica. Impulsionando o retorno das explicações organicistas centradas em distúrbios e transtornos no campo da educação para explicar dificuldades de crianças.

O aliciamento mercadológico da indústria farmacêutica às pesquisas no mundo acadêmico que compelem, pelos seus patrocínios, a muitos estudos com grandes conflitos de interesse. Segundo Angell (2008), algumas pesquisas, em especial de psicofármacos, provêm de resultados inconclusivos, pois testes com placebos têm sido tão eficazes quanto as drogas pesquisadas. Apesar disso, esses resultados têm sido desprezados e produzem-se campanhas que têm se voltado para comercialização em massa de remédios voltados para a área de transtornos mentais e de comportamento na área infância. As formações discursivas advindas do discurso biomédico são cooptadas pela indústria farmacêutica, que por sua vez vão produzindo sentidos para os problemas cotidianos apresentados por crianças e adolescentes e atrelam esses a uma solução rápida via medicamentos.

Nessa perspectiva, nossos entrevistados falam de outros cuidadores, nesse caso os pais ou responsáveis, provindos de dinâmicas familiares despotencializadoras, as famílias aqui pensadas se constituem através de vínculos relacionais complexos e decorrentes de diversos arranjos familiares. Esse desempoderamento dos pais frente às dificuldades de crianças e adolescentes pode ser observado abaixo:

[...] assustador no sentido de que há um desejo dos pais né, de medicar ... o antibiótico no caso, a criança tá com uma febre pode curar, pode ser viral, eu quero um antibiótico, porque eu quero curar rápido, eu não quero esperar o processo que é natural que ele vai formar os anticorpos no corpo dele.... então com esse desejo social dos pais, acaba que o profissional entra nessa seara (SE1).

Eu penso que é um recurso que não deve ser menosprezado... Né, não deve ser menosprezado, eu penso que as abordagens psicológicas, como falei né, com pais, com professores, com as crianças, devem ter precedência, elas devem ter o seu momento, a sua oportunidade (SM1).

Olha, eu acho que falta muito a responsabilização dos pais assim. Os pais tão com dificuldade de cuidar dos filhos, eles estão cheios de dúvidas, falta tempo porque, enfim, eles precisam trabalhar né... Precisam sustentar aquela família. Ahh... E no seu cansaço, muitas vezes acabam delegando esse cuidado pra 
escola, pro serviço de saúde mental, pro projeto [...] Então, eu entendo que os pais estão desesperados, que é complicado é quando esses pais desistem e não 'sei mais o que fazer, ou não tenham mais o que fazer', sempre tem alguma coisa pra fazer. Às vezes eles querem que digamos o que fazer, o que tu vai dizer... tu vai dizer é que pode dar algumas orientações, mas a escolha final é tua.... (CSTOC1).

Segundo Barbiani et al. (2014), a obediência aos especialistas em saúde, na história brasileira, provém das ações em saúde propagadas nos programas de higiene; atualmente e concomitante a isso, cobra-se dos cidadãos e das famílias uma postura ativa na preservação da saúde que passam também a ser tuteladas pelo mercado que invade a vida privada. A medicalização da vida, a higienização de seus costumes, iniciada com a predominância do olhar médico e do seu uso para o controle social, hoje incorpora outros serviços e profissionais de saúde, interesses científicos, políticos e econômicos que a torna um dos maiores fenômenos contemporâneos de mercantilização da sociedade e de seus processos vitais. Segundo os mesmos autores, frente aos problemas, no Brasil, gerados pela urbanização, pauperização da população, as soluções caseiras não faziam frente às disseminações de doenças, com isso, a expansão do saber/poder médico na higienização da sociedade atinge não só o reduto das famílias, como também das escolas. A medicina se forja em uma ciência das doenças, tornou-se pioneira da racionalidade científica e assume uma função catalisadora das ações de saúde "pública", no seio privado da sociedade, assumindo o controle sanitário das famílias. Os preceitos da medicina foram paulatinamente sendo aceitos pelas famílias, acostumadas a serem tratadas e a reagir às ações sanitaristas e policialescas. As normas biomédicas se transformam em desígnios de Lei e são incorporadas pelo Estado, além disso, são aliadas a vocação pedagógica dos educadores como competente ferramenta estratégica na condução das ações médicas. Nas investidas históricas dessa pedagogia higienista, instauradas desde o século passado, a família passou a acolher as influências e as intervenções dos especialistas, numa relação de destituição do seu "saber familiar", de subordinação ao poder externo e às obrigações que passou a assumir perante o espaço público. As orientações criadas pelas famílias são vistas como falhas e os especialistas demandam, prescrevem e exigem maior controle sobre os corpos indisciplinados dos filhos, utilizando-se da pedagogia do consumo para persuadi-las a resolverem seus problemas pela compra de soluções sempre disponíveis. Para todos os males há um "remédio", e para evitá-los basta seguir com disciplina e fé as prescrições dos programas propagandeados na mídia em geral. Notamos isso nas falas abaixo:

[...] tem um Estado aí que, de certa forma, tira a responsabilidade dos pais e acaba tutelando, desde pequeninho [...] Se vê situações extremas de que os pais escutam: ah o médico disse, o professor disse e não há um questionamento dos pais. É assim, ó: faz! Mas há, sim, pais que questionam. Mas, às vezes, são muito pressionados (CVP1).

"Por isso procuram o medicamento: porque tem uma bula lá. Na verdade, as pessoas estão procurando uma receita: como viver? É remédio pra tudo". (CVP2). Ao tomar como base essa perspectiva histórica, Moysés e Collares (2014) ressaltam que a preocupação com as doenças se interpõe à necessidade de construir e olhar a infância, resultando no surgimento do movimento que viria a ser conhecido por Puericultura. Atribuindo as doenças à ignorância da população, pois essa passa a ser grande responsável pelas altas prevalências de doença: a solução só pode ser através do ensino. Neste campo, a Medicina exerce seu papel normatizador com grande eficiência. Não podemos esquecer do avanço sanitário decorrente disso, mas, do mesmo modo, temos que registrar os diferentes usos comerciais e nas condutas frentes as dificuldades de vidas dessas famílias e crianças. Notamos isso, nas falas a seguir:

Então se a gente conseguir conduzir esse processo de maturação do sistema nervoso central e da personalidade sem intervenção farmacológica, muito bom... agora isso também não deve impedir que se faça também uma intervenção farmacológica... manter uma criança usando medicação psiquiátrica desnecessariamente também é um problema... porque eu acho que a gente tem que, também, criança estabilizou o quadro, tentar ir tirando a medicação... as crianças estão mais medicadas, mas eu entendo que isso se deve, em parte, ao melhor conhecimento (SM1).

Daí a cobrança que o médico tenha que resolver o problema [...] aí a demanda por uma orientação e até um tratamento efetivo é bem maior. Ali tu não ficas só na orientação né, tu ficas na questão da ação, de prescrever, indicar o melhor medicamento [...] pode existir essa expectativa de que a gente vai conseguir resolver todos os problemas com o medicamento, mas isso é o menos comum (SG1). 
Como diz Reis (2000), a ideia provinda da eugenia ou do reajustamento psíquico de que como defensor o Estado poderia, com vantagem, através de seus técnicos, tomar para si a tarefa de educação das crianças, sobretudo naquelas famílias "ignorantes da ciência pedagógica" continua muito atuante. Um dos segmentos mais privilegiados de governo das condutas passou a ser a família e, dessa forma, a infância considerada em perigo e perigosa ganha visibilidade política e econômica, como o futuro da Nação (Lemos, 2012). Desde o fim do século XVIII, a família se tornou o agente mais constante da medicalização na qual incide os interesses de Estado, através da política médica, que se delineia como reflexo da (re)organização da família, ou melhor, do complexo família-filhos, como instância primeira e imediata da medicalização dos indivíduos; a família medicalizada-medicalizante (Foucault, 2001). Observamos isso como na fala a seguir:

Alguém sempre sabe mais do seu filho do que tu mesmo. Isso acontece com os professores também. Então o trabalho é de dizer: é teu, no que eu posso contribuir? Mas é isso, é mais um sintoma social mesmo [...]: a criança nasce, já passa pro pediatra [...] medicalizada no sentido de que tem sempre outro pra saber mais dessa criança do que ela própria ou o seus pais (CVP2).

Carvalho, Rodrigues, Costa e Andrade (2015) discutem que há uma expansão sobre os problemas sociais que passam a ser cada vez mais medicalizados e, por sua vez, essa intervenção começa a ser objeto de crítica, devido às posturas, práticas autoritárias de profissionais de saúde e a iatrogênese cultural capaz de provocar a ação autônoma das pessoas para cuidar da própria saúde. Um dos efeitos e produtores disso é o fortalecimento do complexo médico-industrial que na incessante criação de mecanismos de controle produz práticas sociais no interior dos serviços e bens de saúde. Os sujeitos, esses serviços e bens são considerados agentes ativos e centrais da medicalização.

Ela disse que muitas vezes a gente precisa da medicação, que é importante, e claro que é. Eu não discordo, ajuda [... ]. Não sou contra, eu só acho que a gente tinha que rever o que é que tá levando a isso assim né, mas porque será que todo mundo tá precisando de medicação, né? (CSP1).

A partir dessa fala, ressaltamos que esse estudo aborda apenas uma das formas de medicalização da vida, a prescrição de medicamentos às crianças e aos adolescentes. A lógica da biomedicalização, designação mais ampla desse fenômeno, se entende a diversas profissões que se dedicam a outros campos que não os das doenças e das relações com o doente. Como diz Foucault (2010, p. 186) "à patologia se converte em uma forma geral de regulação da sociedade". Aliado a isso, a obrigação permanente que têm os indivíduos, cuidadores, de garantir sua saúde, a saúde de sua família e de seus filhos para poderem viver e, então estudar e trabalhar.

Por outro lado, novas reflexões e formulações preconizam o "empoderamento" dos pacientes e cidadãos que são consumidores ativos e que reconhecem a importância da medicação na conformação de nossa sociedade e o papel destacado das instituições que as fundam, pois produzem bens que proporcionam bem-estar e prazer, formas de conhecer, discursos com capacidade de fabricar novas verdades e técnicas para fazer frente ao mal-estar atual com as mais variadas possibilidades de ação e intervenção sobre o sofrimento humano.

No entanto, como pontua Foucault (2010), isso se entrelaça, a um processo, com novos modos de governar as pessoas, individual e coletivamente que não tem uma essência calcada apenas na medicalização, muito menos, existe um modelo médico único, com efeitos de ação que sejam, necessariamente, o do exercício da disciplina e controle do social, pois a medicalização constitui, em si, prática social e política, e está o tempo todo articulada a outros planos e instâncias de poder micro e macrossociais (Carvalho et al., 2015). No entanto, devemos estar atentos, pois a medicalização vem paulatinamente sendo modificada, cada vez mais dividindo suas antigas atribuições, tanto com outros profissionais de saúde que prescrevem outras terapêuticas dentro dessa lógica, como com novas técnicas biotecnológicas e orientações diversificadas a serem elegidas por novos e diversos domínios. O fenômeno da medicalização é recente e em construção, aberto a disputas de sentido, pois é sensível às mudanças sociais.

\section{Considerações finais}

Esse estudo tem o propósito de provocar uma reflexão que impulsione formas de investir na melhoria da qualidade do cuidado que potencialize a relação dos profissionais de saúde. Para além da criação de instâncias e serviços de diagnóstico e de avaliação de crianças e adolescentes que apresentam dificuldades na sua relação com o mundo. 
A sociedade brasileira vive um processo crescente de medicalização em todas as esferas da vida, pois entende-se por medicalização o processo que transforma, artificialmente, questões não médicas em problemas médicos. Problemas de diferentes ordens são apresentados como "doenças", "transtornos", "distúrbios" que escamoteiam as grandes questões políticas, sociais, culturais, afetivas que afligem a vida das pessoas. Questões coletivas são tomadas como individuais; problemas sociais e políticos são tornados biológicos. Nesse processo, que gera sofrimento psíquico, as pessoas e suas famílias não podem ser unicamente responsabilizadas pelos problemas que enfrentam, enquanto governos, autoridades e profissionais são eximidos de suas responsabilidades. (Manifesto do Fórum sobre Medicalização da Educação e da Sociedade, 2010).

Observamos uma "lógica medicalizante", ou seja, ao produzir sentidos que se orientam na busca de causas orgânicas para problemas de diferentes ordens, induz a um controle e submissão das pessoas, quando silencia questionamentos e inquietudes. Fatores importantes, tais como violências físicas e psicológicas, podem ficar ocultados. Reduzir a complexidade dos sintomas a uma ordem biológica apenas, transforma essas pessoas em "portadores de distúrbios e "diagnósticos" patológicos nos quais medicamentos são a forma central de tratamento. Ao propor terapêuticas e serviços de saúde que simplificam e reduzem as determinações do sofrimento na infância e na adolescência a uma concepção reducionista e biológica, as problemáticas psicopatológicas e seus tratamentos passam a se ancorar apenas nas modificações somáticas, desconsiderando a sua historicidade e contexto. Nessa perspectiva, minavam as possibilidades das pessoas de lidarem com os sofrimentos e perdas decorrentes das formas de viver, transformando as dores do existir em doenças. Portanto, a lógica medicalizante naturaliza, como plausível, os processos e as relações socialmente constituídas em problemas biomédicos.

Consideramos que é fundamental diagnosticar e, se for o caso medicar, mas a partir de uma análise detalhada do que o sujeito diz, de suas produções e de sua história. A partir dessa perspectiva, o diagnóstico deveria ser algo muito distinto de impelir uma lógica medicalizante; passando sim a ser um processo que se constrói ao longo do tempo e que pode ter variações, principalmente quando pensamos na infância e na adolescência (Carta sobre Medicalização da Vida, 2011).
Por isso, frente ao problema da medicalização, profissionais de saúde e serviços de saúde podem atuar para reforçar ou modificar essa situação, pois, de acordo com seu posicionamento, oferecerão atividades num ou noutro sentido, e essa oferta moldará também o tipo de necessidade que emergirá neste contexto. Ou seja, caso assumam uma postura a favor de práticas não medicalizantes, este posicionamento certamente contribuirá para a condução de formas de operar o trabalho que levarão à emergência do tema entre as necessidades dos usuários, bem como à adoção de práticas de cuidado de indivíduos e populações que se disponham a discuti-las (CFP, 2015, p. 20).

Continuaremos a nossa pesquisa, como dizem Tesser, Neto e Campos (2010), para que o trabalho das equipes de saúde possa acolher seus usuários minimizando a medicalização, pois notamos, nas análises das entrevistas, que as intervenções no cuidado às crianças e adolescentes estão pautadas pelos sentidos do discurso das biomedicinas com uma nítida tendência medicalizante. Esperamos que nossas reflexões possam potencializar uma abordagem ampliada desses problemas, trazendo elementos para que, em alguma medida, favoreça a desmedicalização da infância e da adolescência, e que, ao relativizar essa temática, isso permita transformar as formas de cuidar em possibilidade de vínculo, integração e relação entre quem cuida e quem é cuidado.

\section{Referências}

Angell, M. (2008). Companhias farmacêuticas \& médicos: uma história de corrupção. Recuperado de http://www6.ensp.fiocruz.br/radis/ sites/default/files/pdf/companhias-farmaceuticas-e-medicos-umahistoria-de-corrupcao.pdf

Barbiani, R., Junges, J. R., Asquidamine F., \& Sugizaki E. (2014). Metamorfoses da medicalização e seus impactos na família brasileira. Physis Revista de Saúde Coletiva, 24(2), 567-587. doi: 10.1590/S0103-73312014000200013

Carta sobre Medicalização da Vida (2011). Recuperado de http://medicalizacao.com.br/arquivos/Carta-portugues.pdf

Carvalho, S. R., Rodrigues, C. O., Costa, F. D., \& Andrade, H. S. (2015). Medicalização: uma crítica (im)pertinente? Introdução. Physis: Revista de Saúde Coletiva, 25(4), 1251-1269. doi: 10.1590/ S0103-73312015000400011

Conselho Federal de Psicologia - CFP (2015). Recomendações de práticas não medicalizantes para profissionais e serviços de educação e saúde. Recuperado de http://site.cfp.org.br/wp-content/ uploads/2015/06/CFP_CartilhaMedicalizacao_web-16.06.15.pdf

Foucault, M. (1977). Historia de la medicalización. Recuperado de http://hist.library.paho.org/Spanish/EMS/4839.pdf

Foucault, M. (2001). Microfísica do poder. Rio de Janeiro: Graal. 
Foucault, M. (2010). Crise da medicina ou crise da antimedicina. Verve, 18, 164-167. doi: 10.23925/verve.v0i18.8646

Frey, B. N., Mabilde, L. C., \& Eizirik, C. L. (2004). A integração da Psicofarmacoterapia e Psicoterapia de Orientação Analítica: uma revisão crítica. Revista Brasileira de Psiquiatria, 26(2), 118-123. doi: 10.1590/S1516-44462004000200009

Gaudenzi, P., \& Ortega, F. (2012). O estatuto da medicalização e as interpretações de Ivan Illich e Michel Foucault como ferramentas conceituais para o estudo da desmedicalização. Interface, 16(40), 21-34. doi: 10.1590/S1414-32832012005000020

Lefèvre, F. (1987). A oferta e a procura de saúde imediata através do medicamento: proposta de um campo de pesquisa. Revista de Saúde Pública, 21(1), 64-67. doi: 10.1590/S0034-89101987000100010

La Gestion Autonome de La Médication en Santé Mentale - GAM (2006). Regroupement Des Ressources Alternatives En Santé Mentale Du Québec. Repères pour une Gestion autonome de la médication en santé mentale. Guide d'accompagnement. Mon - tréal: Regroupement des Ressources Alter - natives en Santé Mentale du Québec; Équipe de Recherche et d'Action en Santé Mentale et Culture. Recuperado de http://www.rrasmq.com/GAM/documents/textes/GAM_bilan_final_ 2006juin.pdf

Lemos, F. C. S. (2012). Práticas de governo das crianças e dos adolescentes propostas pelo UNICEF e pela UNESCO: inquietações a partir das ferramentas analíticas legadas por Foucault. Psicologia \& Sociedade, 24(spe.), 52-59. doi: 10.1590/S0102-71822012000400009

Manifesto do Fórum sobre Medicalização da Educação e da Sociedade (2010). Recuperado de http://site.cfp.org.br/wp-content/ uploads/2012/07/Caderno_AF.pdf

Mendonça, R. T. (2009). A medicalização de conflitos: consumo de ansiolíticos e antidepressivos em grupos populares (Tese de Doutorado, Universidade de São Paulo, São Paulo). Recuperado de http://www.teses.usp.br/teses/disponiveis/6/6136/tde-28092009164952/pt-br.php

Metzl, J. M., \& Herzig, R. M. (2007). Medicalisation in the 21st century: introduction. The Lancet Journal, 369(9562), 697-698. Recuperado de http://www.thelancet.com/journals/lancet/article/ PIIS0140-6736\%2807\%2960317-1/abstract

Ministério da Saúde (2018). Secretaria de Ciência, Tecnologia e Insumos Estratégicos. Departamento de Assistência Farmacêutica e Insumos Estratégicos. Uso de Medicamentos e Medicalização da Vida: recomendações e estratégias. Brasília: Autor. Recuperado de https://portalarquivos2.saude.gov.br/images/
pdf/2019/fevereiro/14/ERRATA-Livro-USO-DE-MEDICAMENTOSE-MEDICALIZACAO-DA-VIDA.pdf

Montero, F. (1994). Uso racional de psicofármacos y papel de la comunicación social. Acta Psiquiatrica y Psicológica de América Latina, 40(2), 127-137. Recuperado de http://www.acta.org.ar/04-WebForms/ frmlndice.aspx? IdEdicion=83\&ldAbonado=

Moysés, M. A. A., \& Collares, C. A. L. (2014) Mais de um século de patologização da educação. Fórum: Diálogos em Psicologia, ano I(1), 50-64. Recuperado de http://fio.edu.br/revistapsi/arquivos/ revista.pdf

Nardi, H. C., \& Ignácio., V. T. G. (2007). A medicalização como estratégia biopolítica: um estudo sobre o consumo de psicofármacos no contexto de um pequeno município do Rio Grande do Sul. Psicologia \&. Sociedade, 19(3), 88-95. doi: 10.1590/S0102-71822007000300013

Orlandi, E. P. (1999). Análise de Discurso: princípios \& procedimentos. Campinas: Pontes.

Pundik, J. (2009) La medicalización en la infancia. ¿Cada vez más frecuente? Formación Médica Continuada en Atención Primaria, 16(4), 213. Recuperado de https://www.fmc.es/ es-la-medicalizacion-infancia-cada-vez-articulo-13135511

Raeburn, P. (2009). Entre riscos e benefícios. Revista Viver Mente \& Cérebro, (20), 69-75.

Reis, J. R. F. (2000). "De pequenino é que se torce o pepino": a infância nos programas eugênicos da Liga Brasileira de Higiene Mental. História, Ciências, Saúde-Manguinhos, 7(1), 135-157. doi: 10.1590/S0104-59702000000200007

Rodrigues, J. T. (2003). A medicação como única resposta: uma miragem do contemporâneo. Psicologia em Estudo, 8(1), 13-22. doi: 10.1590/S1413-73722003000100003

Rodrigues, M. A. P, Facchini, L. A., \& Lima, M. S. (2006) Modificações nos padrões de consumo de psicofármacos em localidade do Su do Brasil. Revista de Saúde Pública, 40(1), 107-114. doi: 10.1590/ S0034-89102006000100017

Roudinesco, E. (2000). Por que a Psicanálise? Rio de Janeiro: Jorge Zahar.

Sigal, A. M. (2009). Desatenção na infância: um estudo sobre a síndrome de desatenção (ADD). In Escritos metapsicológicos e clínicos (pp. 307-321). São Paulo: Casa do Psicólogo.

Tesser, C. D., Neto, P. P., \& Campos, G. W. S. (2010). Acolhimento e (des)medicalização social: um desafio para as equipes de saúde da família. Revista Ciência \& saúde coletiva, 15(3), 3615-3624. doi: $10.1590 /$ S1413-81232010000900036

Jerto Cardoso da Silva, Doutor em Letras pela Universidade Federal do Rio Grande do Sul - UFRGS, é Professor da Universidade de Santa Cruz do Sul - Unisc. Endereço para correspondência: Av. Independência, 2293, Bloco 31, CEP: 96.815-900, Santa Cruz do Sul - RS. Telefone: (51) 3717-7388. Email: jerto@unisc.br

Caroline Forati Mendes, Psicóloga pela Universidade de Santa Cruz do Sul - Unisc, Mestranda pela Universidade Lusófona de Humanidades e Tecnologias - ULHT. Email: carolineforati@hotmail.com

Recebido em 15.set.17 Revisado em 19.mar.19 Aceito em 31.dez.19 